\title{
Visualising Process: Hofman's 1926 Hamlet Reconstructive Practice
}

\author{
Cat Fergusson
}

\begin{abstract}
This article explores the extant artefacts of Vlastislav Hofman's design process for Karel Hillar's 1926 production of Hamlet. Virtual reconstructive practice has been used to explore Hofman's intentions and process in the development of his visual ideas. This exploration, supported by an analysis of Hofman's critical texts, provides insights into Hofman's developing visual ideas, both in respect of this production and in respect of his wider approach and attitudes to stage space, which might be broadly termed 'Cubist' or 'Expressionist'. A comparison of two distinct scenic styles in this production suggests that Hofman was developing a functional (or in Bourriard's terms, relational) approach to aesthetics which acknowledged the productive role of the audience and invited modes of viewing in which the choice of aesthetic constituted an invitation to dialogue. In this way, we see Hofman developing a scenography that not only 'means' but also invites a discussion of that meaning.
\end{abstract}

\section{Keywords}

theatre, digital, reconstruction, models, VR; scenography, Hamlet, Hofman 
Karel Hugo Hilar's 1926 production of Hamlet at the National Theatre in Prague represents a significant moment in Czech theatre history. This significance extends beyond simple considerations of the careers of the creative team responsible for its vision (though its importance in the careers of both Hofman and Hilar is manifest) and through its approach to literary and dramaturgical concerns it presents an extended commentary on the political, artistic and (perhaps most significantly) social climate of the 1920s. It is not surprising, then, to note that this production has also been the subject of a number of academic studies, most notably Burian's work locating this production within a scenographic tradition of 'designing Hamlet with screens and panels' (BURIAN 2007) and Šormová's work which identifies in this production a deliberate and structured departure, on Hilar's part, from the performance tradition of this text (ŠORMOVÁ and OTČENÁŠEK 2011: 61-78). This article does not aim to revisit these studies, nor to locate this production within a wider performance history, but rather to test a methodological approach which primarily engages with historical material through acts of reconstruction that focus on visual rather than linguistic analysis.

The process of scholarly reconstruction has arguably been an essential part of our understanding of theatre history since Richard Southern's explorations of Georgian theatre practice; but, until relatively recently, reconstructions have tended to take a principally linguistic approach. I use the term 'linguistic' here, to indicate processes in which visual evidence may be described in order to undertake analysis, the outcomes of which may be re-visualised through illustration (or as is the case of Southern's work) physical models. Reconstructions undertaken in this mode have frequently presented valuable insights, but the underlying methodology of 'linguistic' reconstruction requires significant acts of translation and re-translation which inevitably present potential disruptions to meaning that (at the very least) might lead the researcher to modes of analysis which are necessarily reductive. The increasing availability of computer reconstruction to the theatre historian offers the possibility of deploying modes of analysis which are purely visual or spatial. ${ }^{1}$

The value of this kind of engagement with visual material is not limited to the removal of acts of translation but offers an entirely different mode of engagement with historical artefacts. Reconstructive practice offers a lens through which the visual researcher may develop embodied as well as intellectual understanding of the histories in question. Processes of reconstruction which admit visual artefacts directly into propositional models encourage the researcher to conceive of them as materials rather than objects and this has a profound effect not only on the ways in which they are used, but also on the ways in which they are conceived. In his book Making: Anthropology, Archaeology, Art and Architecture, Tim Ingold explores this phenomenon, 'in treating... erstwhile objects as materials we rescue them from the cul-de-sac into which they had

1 It is important to note here that the outcomes of computer reconstruction can be equally problematic. When deployed as illustration or interactive virtual environment, visualised and virtualised outcomes can become a significant impediment to academic discourse as the 'potent visual and kinetic experience of the models 'trumps' the 'state of knowledge' concept (see FAVRO 2006). This article focuses on the development of these models as process. 
been cast and restore them to the currents of life' (INGOLD 2013: 19). For Ingold, this fundamentally changes the way in which 'things' are received, and his characterisation of the relationship between maker and material as 'correspondence' (rather than the more familiar 'interrogation') usefully captures the immediacy of the experience of the visual researcher. ${ }^{2}$ So, we might consider that the usefulness of reconstructive practice lies not in the production of illustration but in its requirement for a procedural engagement with the subject matter. So much so, that the process of reconstruction might often be more appropriately termed 're-enactment', as the researcher not only asks what the architect or scenographer did but also why and (crucially) how.

The principal purpose of the reconstruction that I will here outline, then, is to explore the extant artefacts of this production design with a specific aim of developing a clearer view of Hofman's process rather than Hilar's vision, or any attempt to locate the final production within a broader performance history. For this reason, this article will focus on the extant evidence of Hofman's process rather than Hilar's (which has been documented elsewhere).

Taken together, the overall sense conveyed by the available evidence is of a fluid production; a space sculpted by screens to create a changing architecture for performance. This was not simply achieved by different arrangements of the screens, but photographs suggest that there were also at least 3 different sets of screens used for this purpose (BURIAN 2007). This fluidity is contrasted by the 3 'monolithic' settings of the graveyard and ghost scenes which, in the context of the production as a whole seem to be out of place and representative of a tension between concept and form in Hofman's designs.

In an effort to focus on the designer's process of conceptual development, this reconstruction deals only with the graveyard setting, described in Hofman's renderings as 'Cemetery' (HOFMAN 1926b) and 'Ophelia's Funeral' (HOFMAN 1926c). These renderings are supported by the scale model (HOFMAN 1926a) and production photograph (Unknown 1926).

\section{Context}

As already noted, the 1926 Hamlet is frequently identified as historically significant in the careers of both Vlastislav Hofman and Karel Hugo Hilar. What is perhaps more important for this reconstruction, is that it is also clear that this period was particularly significant to Hofman himself.

Hofman's artistic legacy is manifest, but no less impressive is the significant volume of critical and theoretical writings which both accompany, complement and extend his personal practical and artistic endeavours and also offer reflections on contemporary art and culture. In these writings, we can clearly see an artist/practitioner in an

2 For a more detailed exploration of these methodological concerns see 'Haptic Insights - model making as historical methodology' (FERGUSSON BAUGH 2018). 
almost constant process of self-definition and contextualisation for whom acts of articulation formed an essential artistic process. His 1926 essay 'My Evolution in Theatre' (HOFMAN 1926d) was clearly written after his work on Campaign Against Death which opened in May 1926, just six months before Hamlet, and quite possibly written while he was engaged in developing the design for this production.

It is significant that in this essay Hofman makes a clear effort to 'reframe' his work as a practitioner. The essay is for the most part a retrospective review of his personal development as a stage artist, identifying discrete (though often overlapping) 'periods' in his work, but it concluded with a clear articulation of a current artistic identity and direction. An exploration of his design process on Hamlet considered in the light of his personal reflections on what he called the 'demands of modern theatrical expression' (HOFMAN 1926d) renders further insights into the conceptual development of this design as evidenced through the surviving artefacts of the design process.

In Leading Creators of Twentieth Century Czech Theatre, Jarka Burian describes both Hilar and Hofman as 'expressionists by temperament' (BURIAN 2002). Hofman himself was happy to apply the term to Hilar, but characterised much of his own early work as 'Cubist', though he renders this term ambiguous by describing his work in terms which seem to fall between the two modes:

Exaggerated, broken lines, angled planes [...] subsiding perspective, angled, collapsing, twisted stairs, irregularity, gathering of mass, sharp angles, asymmetrical outlines, secret corners, contrasts of light and shadow. (HOFMAN 1926d)

This ambiguity, no doubt driven in part by national and cultural sensitivities will be familiar to anyone engaged with work from this period, but if we needed to confirm his Expressionist credentials we need look no further than his 1920 design for Les Aubes (HOFMAN 1920) in which the stage space was dominated by towering architectural form and strong contrast - realised in the production through the use of strongly coloured (particularly blue and red) light which sculpted and articulated the stage space, but presented in the design sketches in the form of an overtly Expressionist imitation of woodcut art in the medium of brush and ink drawing on paper. The final scene featured an imposing ziggurat which seems to strongly prefigure Volbrecht's designs for Fritz Lang's Metropolis (1927).

Hofman identified his departure from these tendencies in his 1925 production of Hippodamia in which he 'found it necessary to take a breather from Expressionism' (HOFMAN 1926d), adopting instead a 'simpler line'. He identified this approach to his work as 'Purist', and this is the mode in which he approached the 1926 Hamlet. ${ }^{3} \mathrm{He}$

3 We should note that while this is the mode with which he is most clearly invested in his theoretical exploration. In 'My Evolution in Theatre', Hofman was also simultaneously pursuing an artistic approach which was broadly directed at Constructivist ideals, most obviously in Campaign Against Death which immediately preceded the essay. Here we can see a series of functional platforms with emblematic detail which is at least in part reminiscent of Popova's vision for Meyerhold's Magnanimous Cuckold. This choice of artistic mode (apparently required by the director, Dostal) received some criticism by contemporaries who viewed it as 
articulated the values of this 'Purism' as 'vertical harmony and an exaggeration of the space ... painting gives way to architecture and sculpture'.

Hofman' career is well documented, and evolutions in his preferred aesthetics are of course evident. What is less clear is the way in which he developed his ideas during the design process - as impressive and revealing as his essays and articles are, they are clearly an articulation of Hofman the artist and not Hofman the artisan. In order to develop any understanding of the ways in which Hofman developed visual concepts through the production process one can only explore this discourse through the choices, compromises and resolutions that are implicit in the extant artefacts of the design process. This task is then further complicated by the fact that at times Hofman adopted radically different stylistic approaches to his renderings, even on a single project.

\section{Hofman's Hamlet}

Fortunately, Hofman's work has been extremely well preserved. There is an unusually comprehensive set of visual material available for the 1926 Hamlet, principally in the National Theatre Archive at Terezín and at the National Museum in Prague. Whilst very little of this might be described as of a technical nature (there are for example no technical drawings or illustrations developed for the benefit of construction staff, and none of the remaining illustrations bear the tell-tale marks of the scenic workshop) this material does appear to represent most (if not all) of the design process. While there is no available evidence of initial sketch process there are comprehensive materials covering the various stages of realisation from initial design concept to final production photographs. These materials may be organised into four 'series' of images:

The mixed media images most likely represent the scenographer's initial design 'concept'. They are rendered on a black background, first in white ink outlines and then coloured with pastel and translucent paint (possibly gouache). These images are rendered with extraordinary artistic skill and care and have been exceptionally well preserved. They have been clearly highly valued by the artist and have most probably not been subject to circulation among the production team. They demonstrate a clear sense of artistic and stylistic vision which is unmediated by the limitations of available construction techniques (or indeed at times by the bounds of plausible reality).

The ink on white paper images are presented as a storyboard of sorts, and include a clear sense of performance space, lighting and dramatic potential. The images are rendered with actors at 'nodal moments' of each scene (to use a term later coined by Caspar Neher) to demonstrate a sense of the ways in which the space was intended to function in performance. This identification of key moments had clearly been an important part of Hofman's process from the outset, and is a technique he described in the context of his design for The Hussites:

a simple formal statement and not one which was suited to the dramatic content of the play (see HILMERA 2004). 
I was aiming to 'strengthen the moment'. From the whole spectrum of moods that reign on the stage, always the strongest - the one that lasts through the whole act was chosen. The artistic interpretation of one theatrical moment transformed into an unchanging image of the stage ... An atmosphere always charged with one of the strongest moments of the many that make up the whole play. (HOFMAN 1926d)

So clear is the dramatic narrative in this series of images that it is unlikely that they are a product of Hofman's vision alone but rather the result of a shared understanding of the production concept developed by Hofman and Hilar together. It is possible, then, that these images were produced after the commencement of the rehearsal process.

The model box. For the purposes of this reconstruction, the model box should be regarded as a discrete 'series' of images that complement the design sketches and production photographs. It should also be noted though that there appears to be only one extant example from this series (the graveyard scene). It is not clear whether this is because other elements of the model have been lost, or because other elements of the model were simply never made. Those pieces that do exist are certainly exceptionally well preserved in spite of their obvious fragility; this again suggests that these are artefacts that have been valued. It seems unlikely that they have been circulated or interrogated by scenic artists and while this might indeed suggest this is the only model that was made (if the models did not leave the designer's studio we might expect to find at least elements of other settings preserved with them) but it also suggests that this scene (or at least the scenic realisation of it) was a particularly important part of Hofman's process.

The apparent isolation of this model from the rest of the design process makes it difficult to establish the chronology of this series in relation to other evidence. Traditionally, the creation of a model box forms a relatively early part of the design process and this model is exceptionally well executed with a detailed texture and paint finish which are not evident in the final production photographs. Still, there is no sense that this is in any way a 'sketch' or experimental/provisional model. Yet the absence of any further evidence of model making on this project might suggest either that work on this series was abandoned at a relatively early stage or that this model was specifically created to explore the possibilities of realising only this scene. In either case, it would certainly suggest that Hofman viewed the graveyard scene as central to the play. The model box does however bear sufficient visual similarities with the final setting to support an assumption (with caveats) that it was created after the ink renderings.

The production photographs are clearly the final set of renderings, they represent the scenographer's vision as it was realised in production. Again, there are a comprehensive set of photographs apparently taken from two different points of view (stalls and first circle). It is not clear whether these were taken during a single dress run but many of the images do include performers with the appearance of having been caught 'in action' rather than in a posed photo call. In some images there is a clear attempt to capture some of the more spectacular lighting effects while in others the lighting is 
more broadly demonstrative of attempts to document the setting, which suggests that the photographs were (understandably) not taken under performance conditions.

Taken together the overall sense conveyed by the available evidence is of a fluid production; A space sculpted by screens to create a changing architecture for performance. This was not simply achieved by different arrangements of the screens, but photographs suggest that there were also at least 3 different sets of screens used for this purpose (BURIAN 2007). This fluidity, articulating a performance environment that exemplifies 'vertical harmony and an exaggeration of the space [...] painting gives way to architecture and sculpture' (HOFMAN 1926d), this 'Purist' setting is contrasted by the 3 monolithic settings of the graveyard and ghost scenes which, in the context of Hofman's writing, indeed in the context of the production itself seem to be out of place.

\section{Reconstruction}

In an effort to focus on the designer's process of conceptual development, this reconstruction deals only with the graveyard setting, described in Hofman's renderings as 'Cemetery' (HOFMAN 1926b) and 'Ophelia's Funeral' (HOFMAN 1926c). These renderings are supported by the scale model (HOFMAN 1926a) and production photograph (Unknown 1926).

Stylistic differences between the series complicate processes of comparison. Visual perception is complex and requires significant acts of unconscious interpretation which can be extremely disruptive to processes of critical engagement. Passive attempts to reconcile stylistic differences between the series (and establish a sense of conceptual constancy) lead to a diminished perception of the formal differences. In this way, it becomes easy to interpret each distinctive image as a depiction of the same structure when there are, in fact, profound differences between the structures articulated by Hofman at different points in his design process.

On encountering the images which communicate Hofman's concept, we develop a sense of the structure that they demonstrate; and once we have developed this familiarity we find it difficult to challenge our conceptual model. The operation of processes of conceptual constancy cause us to regard the difference between the images as purely stylistic. Markers which communicate formal difference are reinterpreted stylistically and we tend to modify our interpretation of the images to accept them as representations of the same stage space. They are not.

In order to expose and address these issues of 'critical disengagement', the reconstructions were first undertaken in a way that attempted to capture the stylistic signature of the renderings of each of the representations of the scene (figure 1). This close observation of stylistic elements also greatly assists the processes of 'visual' (rather than 'linguistic') reconstruction as it supports spatial comparisons of the 3-dimensional model and the 2-dimensional image (figure 2). The first stage of the reconstructive process was to establish the implied (or in the case of the two photographs, actual) 


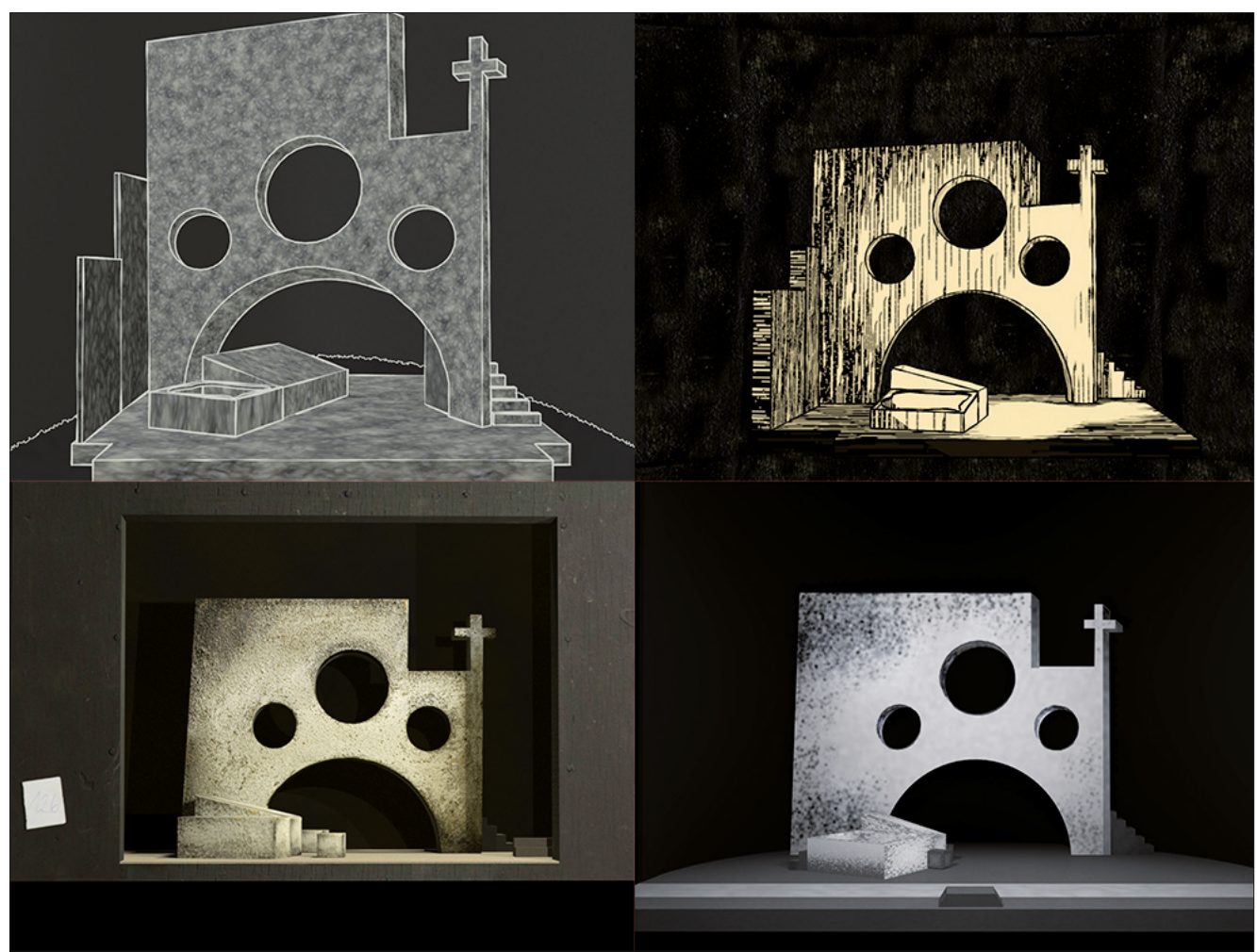

Fig. 1: Computer reconstructions of the designs for the cemetery scene capturing the aesthetic style of the originals (FERGUSSON 2016).

point of view and equivalence of lens focal length. The point of view and approximate focal length of the camera which captured the image of the model box was known, but the details of the other images were established as part of the modelling process through a comparative exploration of lines of perspective - principally using the stage floor and steps as a guide.

Once the point of view for the reconstructions was established, the images formed a guide for the placement and scale of the remaining elements (wall, stage right return, masking, cyclorama and graves). Once the four reconstructions were complete, the problems presented by perceptual attempts to develop a sense of conceptual constancy were addressed by removing stylistic differences and presenting the models from a uniform point of view and in a neutral style - in this case simple line drawing (figure 3). Formal differences can then be exposed through a process of 'morphing' between the different models, focusing the viewer on issues of difference rather than consonance.

Hofman's original design for the graveyard scene is profoundly different in style to almost all of his other renderings for this production. Given the views that he expressed in 'My Evolution in Theatre', it is particularly interesting that this difference takes the form of a clear debt to Cubo-Expressionism. The image itself is rendered with no fixed 


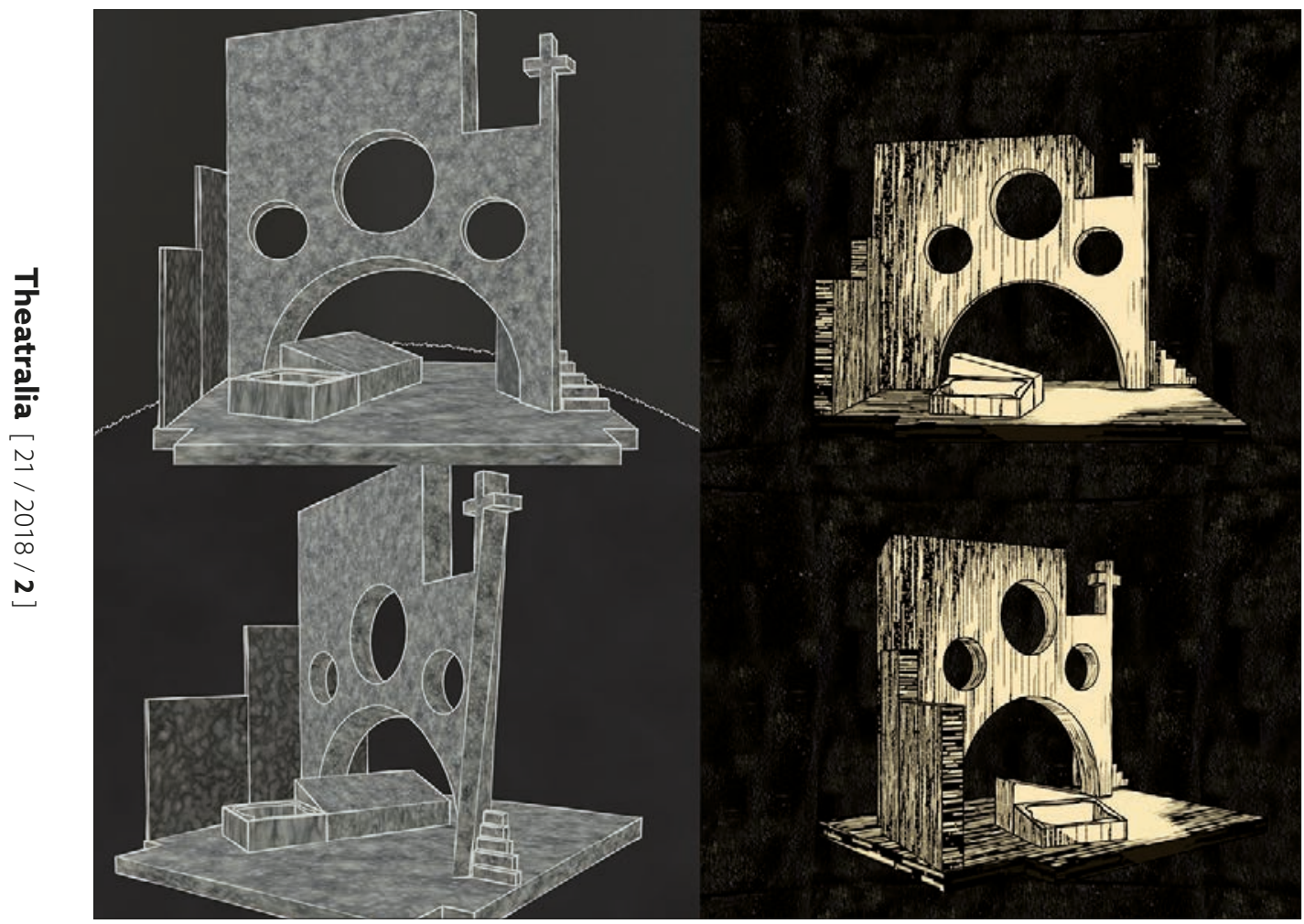

Fig. 2: Reconstructions of illustrations explored as three dimensional models (FERGUSSON 2016).

point of view. Instead it is formed from a collage of at least six simultaneous alternative viewpoints. For the purposes of the reconstruction, a point of view has been derived from the stage floor but it has been necessary to significantly deform other elements of the setting in order to capture this sense of simultaneity and conform to Hoffman's rendered image.

This distinctly Cubist view of the set is compounded by Expressionist distortions of height and depth and an overall exaggeration of vanishing point perspective. The virtual reconstruction demonstrates the extent of the distortion required to realise this 'capricious perspective', which is only truly apparent when departing from the implied point of view of Hofman's rendered image (figure 2).

While many other extant images of this production demonstrate a vertical harmony and exaggeration of space (in line with Hofman's Purist ideals), only the mixed media renderings of the graveyard scene and the scenes conceived for the Ghost of Hamlet's Father retain this strong sense of Cubo-Expressionism.

Given the development of other scenes along Purist lines and the later revision of the graveyard scene, it seems likely then that these designs, aligned as they are to ideas that Hofman was in the process of rejecting in his critical work (possibly even as he was designing them), were among the first that he conceived, but this significant difference 


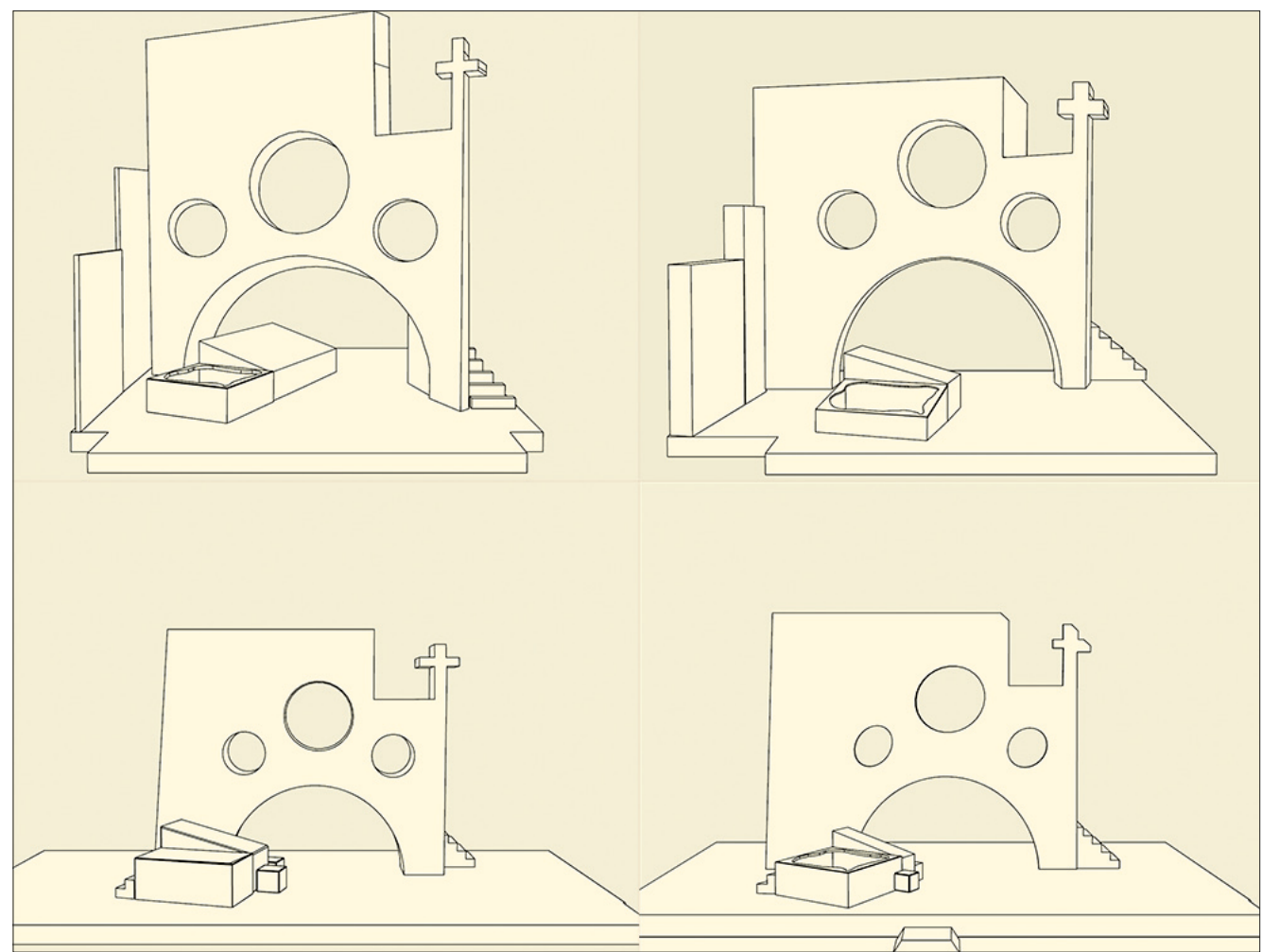

Fig. 3: Neutral rendering of the set during development, showing formal differences (FERGUSSON 2016).

in aesthetic approach might also suggest that Hofman viewed these scenes (the graveyard scene and the two appearances of the Ghost of Hamlet's Father) as qualitatively different in the context of this production. The choice of the Cubo-Expressionist aesthetic then may have a significance beyond the manifestation of a developing stylistic approach.

In her examination of Meyerhold's deployment of stage cubism, Skinner has identified that in the difference between referenced Cubist art and actual stage reality there exists a gap which invites analysis. 'Similarities and differences between the canvas and the stage are fundamental [...] it is through these differences that the analysis functions' (SKINNER 2015). Skinner proposes that in Cubist staging there existed a tension between depth and surface that must be negotiated by the viewer (the fine artist may choose not to resolve this tension but the stage artist cannot) and this inevitably establishes a dialogue between realist and abstract concerns. Furthermore, existence of this ambiguity requires a different form of engagement from the audience as the use of foreshortened (or in the case of the Hofman design 'capricious') perspective undercuts the notion of objectivity in viewing by challenging the belief that 'the spectator needs to occupy a position external to the performance in order to appreciate it' (SKINNER 2015). 


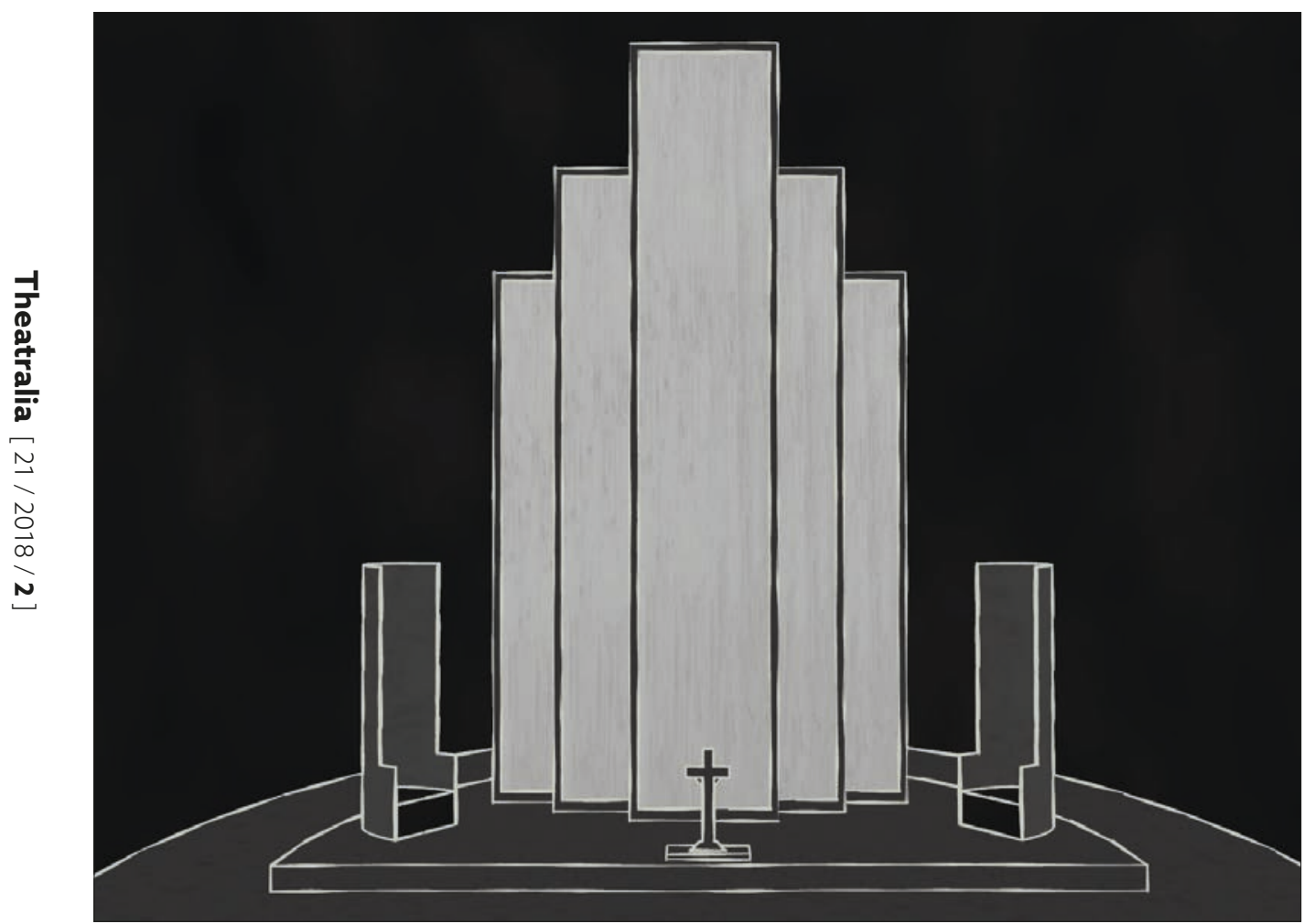

Fig. 4: Reconstruction of Hofman's design for 'other scene with the king' (FERGUSSON 2016).

If the use of Cubist (or Cubo-Expressionist) aesthetics invites the audience to occupy the frame of the performance, the deployment of screens arranged with diminishing perspective (and reminiscent of neo-classical perspectival staging) has the opposite effect. Designs for scenes set in Claudius' home (figure 4) and the garden demonstrate a clear sense of diminishing perspective which reinforces a sense that the stage image may only be resolved from a single fixed external and definitive point of view.

The choice of different aesthetic approaches then, might indicate that Hofman at least intended that the role of the audience should change during the performance. The adoption of a stylistic approach which encourages challenges to the authority of presentation in scenes which deal with existential matters - with the exception of the famous 'to be or not to be' speech in which Hamlet was placed external to the scene in black 'null' space (see ŠORMOVÁ and OTČENÁŠEK 2011) - takes on a greater significance.

Hofman had addressed this kind of acknowledgement of aesthetic as meaning in its own right in his 1913 essay 'The stage shaped pictorially' in which he makes a very clear statement that 'the stage set as an independent expression, shaped by artifice, as effect for the sake of effect, is actually a work of art' (HOFMAN 1926e). This sentiment is echoed in Bourriaud's work Relational Aesthetics. Bourriaud claims that one can no longer 
consider the content of an artwork aside from its aesthetic as this represents an active choice by the artist that constitutes an invitation to dialogue with the viewer, and in this regard aesthetic should not be considered as 'form' but the more active 'formation'.

In observing contemporary artistic practices, we ought to talk of 'formations' rather than 'forms'. Unlike an object that is closed in on itself by the intervention of style and a signature, present-day art shows that form only exists in the encounter and in the dynamic relationship enjoyed by an artistic proposition with other formations, artistic or otherwise (BOURRIAUD 2002).

If we are to accept that art is 'relational' in this way - a founding principle of dialogue - then Hofman's Cubo-Expressionist settings represent an invitation to engage with this dialogue and in Bourriaud's model, this 'inter-subjectivity does not only represent the social setting for the reception of art ... but also becomes the quintessence of artistic practice' (BOURRIAUD 2002). It is only through dialogue that form is granted productive status.

In the setting represented on the pen and ink rendering of the scene, Hofman has clearly rejected much of the Cubist intent of the mixed media image - though some Expressionist sense of exaggerated perspective remains. The virtual model of this rendering again reveals a setting which must undergo some contortions in order to achieve the reality of the original drawing, but those contortions are now much less pronounced and actually physically possible. So, while 'My Evolution in Theatre' suggests a move away from Cubo-Expressionism - a suggestion which is supported by his execution of other designs for this production - there are clear attempts to capture (or at least exploit) some of the Expressionist tendencies evident in the mixed media rendering in other series of images. Only in the model box are these tendencies completely absent.

The model does show painting clearly giving way to architecture and sculpture, but this 'monolithic' setting seems to be a comprehensive departure from the artistic and conceptual principles that underpin the rest of Hofman's process on this production. In the context of Hofman's essay, this artefact seems to be a rejected experiment. Indeed, the absence of other model box elements suggests that this is perhaps genuinely the case - if a more complete model ever existed, this setting was apparently not part of it. It is clear that this model box captures none of the extended artistic commentary of the designer's two-dimensional renderings - this setting is functional but it is not expressive.

It may be that in modelling the architectural form of the graveyard scene, Hofman discovered that any attempts to capture his original vision in three-dimensional form were ultimately futile (or at least very expensive). The contortions evident in the virtual model of the mixed media rendering were almost certainly beyond the budget (if not the technology) of the production, but the sense of shifted perspective was clearly so important to him (or possibly to Hilar) that it was retained and ultimately realised by way of a painted flat. It is clear from the production photographs that this pragmatic solution was not without compromise, while the upper windows relate a sense of painted depth, this has clearly been removed where ambiguous perspective was most 
directly brought into contact with living, three-dimensional reality (in the acting space under the arch where there is no evidence of there being a painted 'return' as there is in the upper windows $\left.{ }^{4}\right)$. So while it clearly contradicted his Purist ideals, this use of painted scenery was the only solution available to Hofman to realise the more CuboExpressionist scenes of the graveyard and ghost scenes (where even the white lines of the mixed media rendering were retained in production). It is worth noting that while the use of Cubist aesthetics in stage space can be difficult to negotiate, Hofman has addressed some of the more practical difficulties caused by the tensions between depth and surface by presenting his Cubo-Expressionist settings as a single unchallenged monolithic flatness in which the isolation offered by the black cyclorama becomes a critical element. Indeed, the mixed media designs show that it is in these settings that the curtain is most clearly observed.

So, it appears that Hofman has used this production to explore the possibility of developing a scenography that not only 'means' but also invites a discussion of that meaning. Perspectival space framed by screens is suggestive of a performance environment in which meaning is fixed by an external view which the audience is invited to adopt, but scenes which deal with spiritual or supernatural matters adopt a distinctly Cubist mode of presentation which openly invites interpretation (and suggest the possibility that individual views may differ). So while it may be a step too far to suggest that in his use of this aesthetic in the ghost and graveyard scenes, Hofman presents us with an extended metaphor for the death of scenic Expressionism, this is certainly a production in which Hofman presents us with a stage set that is indeed an 'independent expression shaped by artifice', a 'formation' that only really exists in the encounter between the audience and the production. In the context of Hofman's essay, we might see this as a production in which we can observe a stylistic evolution, a moment of change captured mid step; but, in Bourriaud's terms, the existence of the two modes is an essential part of this formation: because it is only in its dynamic relationship with other formations that an artistic proposition is granted productive status.

So, while the overall impression of this production is of a fluid space, sculpted by screens, it is clear that the juxtaposition of this mode with one which more explicitly acknowledges the productive role of the audience was an essential element of Hofman's vision. So much so, that the deployment of this second mode has been the subject of an extended process of pragmatic compromise and what we see in Hofman's process for the graveyard scene is a clear statement of Cubo-Expressionist intent, first tamed (in the storyboard) and then removed (in the model box) before being re-instated (in the production photographs) in a way which represents a pragmatic compromise between the designer's apparent intent and the technical requirements of stage realisation and this is a process that we see (at least in part) reflected in this production as a whole.

4 It is clear from both storyboard sketches and narrative accounts that performers did appear in these windows during Ophelia's funeral but the conflict between real actors and painted scenery is more significant where these actors are a focus of action and in front of the scenery. For the chorus at the window, it is possible to 'cheat' the perspective in a way which renders the conflict less problematic. 


\section{Bibliography}

BOURRIAUD, Nicolas. 2002. Relational Aesthetics. Dijon: Presses du Reel, 2002.

BURIAN, Jarka. 2002. Leading Creators of Twentieth-Century Czech Theatre. London: Routledge, 2002.

BURIAN, Jarka. 2007. Designing Hamlet with Screens and Panels. TDE्TT 43: 2: 16-26.

FAVRO, Diane. 2006. In the Eyes of the Beholder: virtual reality re-creations and academia. Imaging Ancient Rome:Documentation, Visualisation, Imagination, Rome 20 (3. 5. 2004).

FERGUSSON, Cat. 2016. Vlastislav Hofman's 1926 designs for Hamlet. Reconstruction Practice.

FERGUSSON BAUGH, Cat. 2018. Haptic Insights - Modelmaking as Historical Methodology. Theatre and Perfomance Design 4: 1.

HILMERA, Jiří. 2004. Vlastislav Hofman, Stage Designer. In Vlastislav Hofman. Prague: Společnost Vlastislava Hofmana a ÚDU AV ČR.

HOFMAN, Vlastislav. 1920. Five Set Designs for Les Aubes. Prague: Národni Muzeum.

HOFMAN, Vlastislav. 1926a. Design for Hamlet - Cemetary. Prague: Národni Divadlo.

HOFMAN, Vlastislav. 1926b. Design for Hamlet - Hřbitov (Cemetary). Prague: Národni Muzeum.

HOFMAN, Vlastislav. 1926c. Design for Hamlet - Pohřeb Ofelie (Ophelia's Funeral). Prague: Národni Divadlo.

HOFMAN, Vlastislav. 1926d. My Evolution in Theatre. In Miroslav Rutte and Josef Kodíček (eds.). Nové čské divadlo 1918-1926: sbornik dramatického svazu. Prague, 1926: 70-80.

HOFMAN, Vlastislav. 1926e. The Stage Shaped Pictorially. In Miroslav Rutte and Josef Kodíček (eds.). Nové české divadlo 1918-1926: sbornik dramatického svazu. Prague, 1926: 386-387.

INGOLD, Tim. 2013. Making: Anthropology, Archaeology, Art and Architecture. New York: Routledge, 2013.

SKINNER, Amy. 2015. Meyerhold and the Cubists: Perspectives on Painting and Performance. Bristol: Intellect, 2015.

ŠORMOVÁ, Eva and Štěpán OTČENÁŠEK (eds.). 2011. Czech Theatre Review 1989-2009: selected articles on Czech theatre from the journal Divadelni Revue. Praha: Institut Umění - Divadelní Ústav, 2011.

Unknown. 1926. Hamlet - Graveyard Scene. edited by Unknown.

\section{Cat Fergusson}

School of Arts

Gulbenkian Centre, University of Hull, United Kingdom

c.fergusson-baugh@hull.ac.uk

Cat Fergusson teaches applications of digital technologies in theatre and performance at the University of Hull. She has worked in the area of digital reconstruction of extant and historic theatrical spaces since 1995 and has had work exhibited at the Victoria and Albert museum and the Columbus Museum of Art. 